\title{
Meteoric smoke concentration in the Vostok ice core estimated from superparamagnetic relaxation and some consequences for estimates of Earth accretion rate
}

\author{
Luca Lanci, ${ }^{1}$ Dennis V. Kent, ${ }^{2,3}$ and Pierre E. Biscaye ${ }^{3}$ \\ Received 26 February 2007; revised 10 April 2007; accepted 17 April 2007; published 18 May 2007.
}

[1] We measured the magnetization of glacial and interglacial ice from the Vostok core to estimate the meteoric smoke concentration in Antarctic ice. We have found that, within the uncertainty of the method, the smoke concentration in ice in Antarctica is equivalent to that previously measured in Greenland ice. The virtually identical smoke concentrations despite the different ice accumulation rates in Greenland and Antarctica suggest that wet deposition is the main deposition mechanism for such ultra-small particles. Given the typical scavenging ratios for atmospheric aerosols, this would imply that previous estimates of accretion rate based on dry deposition are likely to be appreciably overestimated. Citation: Lanci, L., D. V. Kent, and P. E. Biscaye (2007), Meteoric smoke concentration in the Vostok ice core estimated from superparamagnetic relaxation and some consequences for estimates of Earth accretion rate, Geophys. Res. Lett., 34, L10803, doi:10.1029/2007GL029811.

\section{Introduction}

[2] Aerosol reaching polar regions is mostly composed of dust originating in desert areas and includes some fraction of magnetic minerals, which can be magnetized and measured in the laboratory as an isothermal remanent magnetization (IRM) [Lanci et al., 2001]. The IRM of ice is thus expected to be linearly correlated with dust concentration and measurements on Greenland (NorthGRIP) ice samples have showed that this is indeed the case [Lanci et al., 2004]. However, this work also revealed that a large portion of the IRM is carried by highly magnetic, nanometric-sized particles that were explained as fallout of meteoric smoke [Lanci and Kent, 2006]. These nanoparticles originated from atmospheric ablation of meteorites and micrometeorites at high $(\sim 100 \mathrm{~km})$ altitude [Hunten et al., 1980; Helmer et al., 1998; McNeil et al., 1998] and are transported in the stratosphere mostly over the poles during the winter season by atmospheric circulation [Prather and Rodriguez, 1988]. There is now direct evidence for the existence of these particles in the atmosphere [Lynch et al., 2005; Rapp et al., 2005] and Lanci and Kent [2006] showed that magnetic estimates of the concentration of meteoric smoke that accumulated in Greenland ice are in excellent

\footnotetext{
${ }^{1}$ Faculty of Science and Technology, University of Urbino, Urbino, taly.

${ }^{2}$ Department of Geological Sciences, Rutgers University, Piscataway, New Jersey, USA.

${ }^{3}$ Lamont-Doherty Earth Observatory, Palisades, New York, USA
}

Copyright 2007 by the American Geophysical Union. 0094-8276/07/2007GL029811\$05.00 agreement with iridium-based measurements [Gabrielli et al., 2004]. However, Earth accretion estimates are computed based on the hypothesis of dry deposition, with snow accumulation diluting the smoke fallout. In order to test this hypothesis, we apply magnetic techniques to Antarctic ice to obtain an independent estimate of meteoric smoke concentration in a region with a different ice accumulation rate.

\section{Measurement Procedure and Results}

[3] We performed IRM measurements following previously described procedures [Lanci et al., 2004; Lanci and Kent, 2006] on 70 ice samples from the Vostok ice core $\left(78^{\circ} 28^{\prime} \mathrm{S}, 106^{\circ} 48^{\prime} \mathrm{E}\right.$; Figure 1$)$ at 10 levels between $140 \mathrm{~m}$ and $500 \mathrm{~m}$ depth that represented the Holocene and the last glacial maximum (Figure 2). An IRM was induced in each sample (typically $\sim 50 \mathrm{~g}$ ) with a pulse magnetizer up to the maximum field of $1 \mathrm{~T}$ and the magnetizations were measured immediately after each step, all the while maintaining the sample close to liquid nitrogen temperature $(77 \mathrm{~K})$. After the measurements, the samples were allowed to re-equilibrate to storage freezer temperature (about $255 \mathrm{~K}$ ) for a few hours and were measured again immediately after re-immersion in liquid nitrogen. The resulting IRM of the ice samples had decreased compared to their previously measured value, suggesting the relaxation of remanence of the finest (i.e., superparamagnetic or SP) particle fraction, between $\sim 5 \mathrm{~nm}$ and $30 \mathrm{~nm}$ diameter [Lanci and Kent, 2006]. The contribution of the SP fraction was computed for each sample by subtracting the IRM remaining after relaxation at $255 \mathrm{~K}$ (ST, stable magnetization) from the IRM attained just after exposure to the maximum field. The exponential dependence of relaxation time with respect to magnetization and temperature makes the determination of the SP and ST components relatively insensitive to the elapsed time for temperature re-equilibration.

[4] A comparison of magnetization (SP and ST) and dust measurements for Vostok [Petit et al., 1999] indicates that they are clearly correlated (Figure 2), which is the same pattern observed in the NorthGRIP results [Lanci and Kent, 2006]. Moreover, the variability of the ST magnetization as indicated by the standard deviations is comparable to that of the dust concentrations, although the lower resolution of the available dust data does not allow a detailed comparison. A relatively high SP fraction was found in Vostok ice, with a relatively large background value that is actually higher than ST magnetization when dust concentrations are low during the Holocene (to $\sim 350 \mathrm{~m}$ ) although SP values are less elevated than ST magnetization when dust concentrations are generally high in the last glacial maximum 


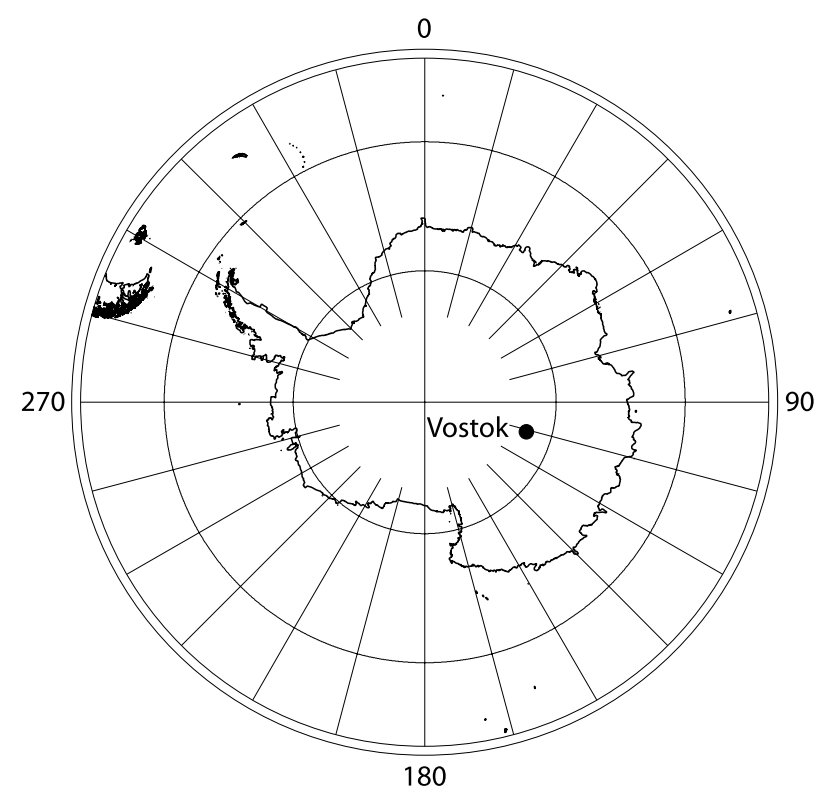

Figure 1. Location of Vostok ice core.

( $\sim 350-500 \mathrm{~m})$. We cannot exclude the possibility that part of the magnetic relaxation may be due to large multidomain grains (>1000 nm for magnetite), which can loose some of their magnetization by warming through the Verwey transition [e.g., Dunlop and Özdemir, 1997]. However, most of them (those larger than $1300 \mathrm{~nm}$ ) are recognized in grain-size analysis, and thus, they are not included in the offset of dust magnetization [Lanci and Kent, 2006]. For interglacial samples, the loss of magnetization is so large that it would require an unrealistically large fraction of large multi-domain grains that somehow escaped detection by grain size analyses; for glacial samples, large multi- domain particles are likely to be included in the dust measurements and this will tend to factor out their influence on the relaxation magnetization that is uncorrelated to dust concentration.

[5] We assume that the terrestrial dust component has a constant ST/SP ratio, which is supported by the linear correlation of the ST and SP magnetizations (Figure 3), and that the concentration of meteoric smoke is constant over glacial and interglacial times. We neglect any significant climatic control on the grain-size distribution of the magnetic particles, based on the qualitative linear correlation between dust and ST magnetization (Figure 2) and by the linear correlation of ST and SP magnetizations (Figure 3). We also disregard the possibility that the meteoritic component contributes significantly to the ST magnetization (i.e., it has a grain size larger than $30 \mathrm{~nm}$ ) on the basis of the zero intercept obtained from regression of the stable magnetization versus dust concentration in NorthGRIP ice [Lanci and Kent, 2006] as well as the very low stable (ST) magnetization values for Holocene ice at Vostok (Figure 2). The linear correlation between SP and ST (Figure 3) thus reflects a common terrestrial dependence, whereas the significant positive offset in the linear regression is explained as the uniform meteoric contribution to SP magnetization. The best estimate of the meteoric smoke magnetization, calculated on the basis of mean values of SP and ST magnetization at each level and taking into account errors in both coordinates in the linear regression, is $8.1 \pm$ $2.7 \times 10^{-9} \mathrm{Am}^{2} \mathrm{~kg}^{-1}$ (1 $\sigma$ uncertainty of the regression line); a similar magnetization is obtained using singlesample values of SP and ST in the regression.

[6] The concentration of meteoric smoke can be estimated from the ice magnetizations by assuming that all available iron in the meteoritic source was oxidized to magnetite $\left(\mathrm{Fe}_{3} \mathrm{O}_{4}\right)$, which for the average composition of ordinary chondrites, the most common type of meteorite [Lodders

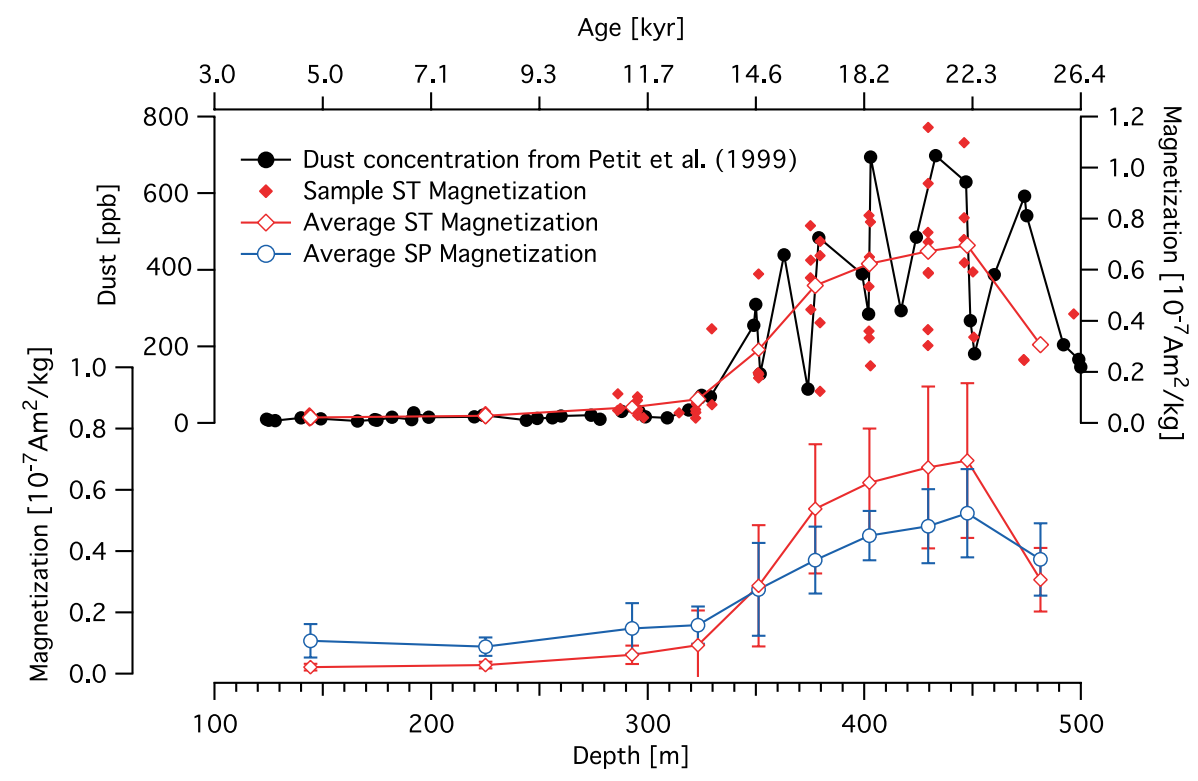

Figure 2. Ice magnetizations (stable and superparamagnetic) compared with dust concentration [Petit et al., 1999] in the Vostok ice core over the last glacial and interglacial (Holocene) intervals. ST magnetizations (samples as closed diamonds, interval averages as open diamonds) more closely follow the changes in dust concentration than the SP magnetizations (open circles), which include a significant contribution from meteoric smoke. Age scale from Petit et al. [1999]. 


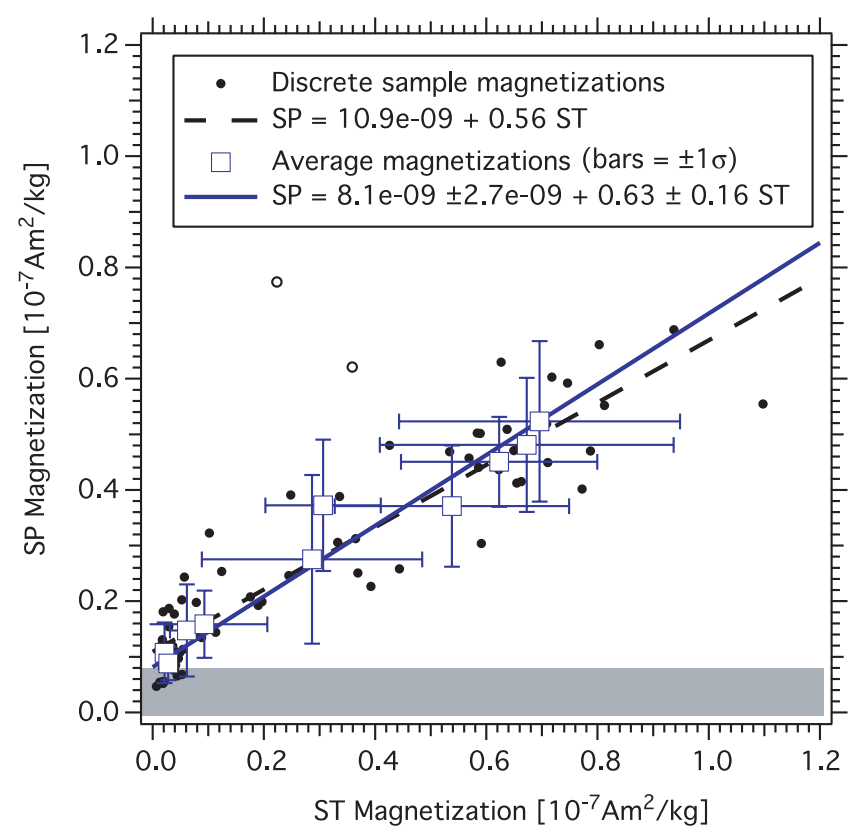

Figure 3. Correlation between ST, a proxy for terrestrial dust, and SP, a proxy for a combination of terrestrial dust and meteoric smoke. The non-zero SP intercept of the linear regression (gray band) is interpreted as the best estimate of the ice magnetization due to meteoric smoke. Linear regressions were computed both for the averaged groups of data (solid line, open squares with 1 sigma error bars) and for single data points (dashed line, closed circles) taking into account errors in both coordinates. Open circles represent two outlier samples that were discarded from linear regression.

and Fegley, 1998], gives an expected saturation magnetization $\left(\mathrm{M}_{\mathrm{s}}\right)$ for the meteoric smoke particles in the ice of $30 \mathrm{Am}^{2} \mathrm{~kg}^{-1}$ and a corresponding saturation IRM $\left(\mathrm{M}_{\mathrm{r}}\right)$ of about $50 \%$ of that value (assuming $\mathrm{M}_{\mathrm{r}} / \mathrm{M}_{\mathrm{s}}=0.5$ ) [Lanci and Kent, 2006]. For NorthGRIP ice in Greenland, we obtained a smoke concentration of $0.78 \pm 0.25 \mathrm{ppb}$ [Lanci and Kent, 2006] which, given the above assumptions, corresponds to a Fe concentration of $0.19 \mathrm{ppb}$. This estimate compares well with a concentration of $0.18 \mathrm{ppb}$ for chondritic Fe inferred from independent Ir measurements at the same site [Gabrielli et al., 2004]. The virtually identical results obtained from iridium and magnetic measurements in NorthGRIP ice support the assumed value of smoke magnetization and an $\mathrm{M}_{\mathrm{r}} / \mathrm{M}_{\mathrm{s}}$ ratio of 0.5 and allow us to apply the same technique in Vostok ice in Antarctica, even though iridium measurements are not available for this ice core. Following this approach we obtain a Fe concentration of $0.13 \mathrm{ppb}$ and a corresponding smoke concentration in Antarctic ice of $0.53 \pm 0.18 \mathrm{ppb}$, where the quoted error simply indicates the uncertainty of the regression line.

\section{Discussion and Conclusions}

[7] Meteoric smoke flux can be computed at the Vostok site by multiplying the smoke concentration $(0.53 \pm$ $0.18 \mathrm{ppb})$ by the local snow accumulation rate $\left(\sim 20 \mathrm{~kg} / \mathrm{m}^{2} / \mathrm{yr}\right.$; [Petit et al., 1999]), which gives a flux of $1.1 \pm 0.35 \times$
$10^{-8} \mathrm{~kg} / \mathrm{m}^{2} / \mathrm{yr}$. Extrapolated over the entire planet, this flux value would imply an Earth accretion rate of $5.4 \pm 1.8 \mathrm{kt} / \mathrm{yr}$. Such an accretion rate is about one order of magnitude smaller than the $64 \pm 18 \mathrm{kt} / \mathrm{yr}$ estimated from NorthGRIP ice in Greenland, the difference mainly arising from the $8 \mathrm{x}$ larger snow accumulation rates at NorthGRIP $\left(\sim 160 \mathrm{~kg} / \mathrm{m}^{2} / \mathrm{yr} ;\right.$ [North Greenland Ice Core Project Members, 2004]) because our estimates of meteoric smoke concentration in the two regions are rather similar $(0.78 \pm 0.25 \mathrm{ppb}$ in Greenland vs. $0.53 \pm 0.18 \mathrm{ppb}$ in Antarctica). The similar smoke concentration suggests that wet deposition may be the main process of deposition of nanometric-sized particles whereby smoke concentration in ice largely reflects that of the atmosphere [Alley et al., 1995]. The slightly smaller smoke concentration in Vostok ice compared to NorthGRIP ice could be explained by the effect of wet deposition removing more smoke from the air parcel as it travels toward the higher latitude of the Vostok core. Extrapolation of an Earth accretion rate from local fluxes governed by wet deposition would thus be highly dependent on local precipitation rates.

[8] Pending the availability of more accurate models of the depositional process, a crude approximation of accretion rate can be made from estimates of the concentration in the atmosphere through the scavenging ratio and assuming an equilibrium state between input and deposition. Given typical scavenging ratios for atmospheric aerosols that range from 200 to 2000 [Duce, 1995], a total mass of atmosphere of $5.15 \times 10^{18} \mathrm{~kg}$, and a nominal smoke residence time in the atmosphere of 12-16 months [World Meteorological Organization, 1998], maximum estimates of Earth accretion rate range from $9 \mathrm{kt} / \mathrm{yr}$ to only $18 \mathrm{kt} / \mathrm{yr}$ (mean $14 \mathrm{kt} / \mathrm{yr}$ ) from Vostok ice in Antarctica and from $14 \mathrm{kt} / \mathrm{yr}$ to only $26 \mathrm{kt} / \mathrm{yr}$ (mean $20 \mathrm{kt} / \mathrm{yr}$ ) for NorthGRIP ice in Greenland. These maximum accretion rates fall close to the lower tail of the $40 \pm 20 \mathrm{kt} / \mathrm{yr}$ range proposed by Love and Brownlee [1993] from direct satellite measurements and suggest that previously computed accretion rates from Greenland ice ( $\sim 78 \mathrm{kt} / \mathrm{yr}$ [Gabrielli et al., 2004] or $\sim 64 \mathrm{kt} / \mathrm{yr}$ [Lanci and Kent, 2006]) are likely to be overestimated by at least a factor of two.

[9] Acknowledgments. We thank Andrew Roberts and an anonymous reviewer for constructive comments. This research was supported by grants from the Office of Polar Programs of the National Science Foundation. Lamont-Doherty Earth Observatory contribution 7031.

\section{References}

Alley, R. B., R. C. Finkel, K. Nishiizumi, S. Anandakrishnan, C. A. Shuman, G. R. Mershon, G. A. Zielinski, and P. A. Mayewski (1995), Changes in continental and sea-salt atmospheric loadings in central Greenland during the most recent deglaciation, J. Glaciol., 139, $503-514$.

Duce, R. A. (1995), Sources, distributions, and fluxes of mineral aerosols and their relationship to climate, in Aerosol Forcing of Climate, edited by R. J. Charlson and J. Heintzenberg, pp. 43-72, John Wiley, Chichester, UK.

Dunlop, D. J., and O. Özdemir (1997), Rock Magnetism: Fundamentals and Frontiers, 573 pp., Cambridge Univ. Press, Cambridge, UK.

Gabrielli, P., et al. (2004), Meteoric smoke fallout over the Holocene epoch revealed by iridium and platinum in Greenland ice, Nature, 432, $1011-$ 1014.

Helmer, M., J. M. C. Plane, J. J. Qian, and C. S. Gardner (1998), A model of meteoric iron in the upper atmosphere, J. Geophys. Res., 103, 10,91310,926 . 
Hunten, D. M., R. P. Turco, and O. B. Toon (1980), Smoke and dust particles of meteoric origin in the mesosphere and stratosphere, J. Atmos. Sci., 37, 1342-1357.

Lanci, L., and D. V. Kent (2006), Meteoric smoke fallout revealed by superparamagnetism in Greenland ice, Geophys. Res. Lett., 33, L13308, doi:10.1029/2006GL026480.

Lanci, L., D. V. Kent, P. E. Biscaye, and A. Bory (2001), Isothermal remanent magnetization of Greenland ice: Preliminary results, Geophys. Res. Lett., 28, 1639-1642.

Lanci, L., D. V. Kent, P. E. Biscaye, and J. P. Steffensen (2004), Magnetization of Greenland ice and its relationship with dust content, J. Geophys. Res., 109, D09104, doi:10.1029/2003JD004433.

Lodders, K., and B. J. Fegley (1998), The Planetary Scientist's Companion, 371 pp., Oxford Univ. Press, New York.

Love, S. G. (1993), A direct measurement of the terrestrial mass accretion rate of cosmic dust, Science, 262, 550-553.

Lynch, K. A., L. J. Gelinas, M. C. Kelley, R. L. Collins, M. Widholm, D. Rau, E. MacDonald, Y. Liu, J. Ulwick, and P. Mace (2005), Multiple sounding rocket observations of charged dust in the polar winter mesosphere, J. Geophys. Res., 110, A03302, doi:10.1029/ 2004JA010502.

McNeil, W. J., S. T. Lai, and E. Murad (1998), Differential ablation of cosmic dust and implications for the relative abundances of atmospheric metals, J. Geophys. Res., 103, 10,899-10,912.
North Greenland Ice Core Project Members (2004), High-resolution record of Northern Hemisphere climate extending into the last interglacial period, Nature, 431, 147-151.

Petit, J. R., et al. (1999), Climate and atmospheric history of the past 420,000 years from the Vostok ice core, Antarctica, Nature, 399, 429436.

Prather, M. J., and J. M. Rodriguez (1988), Antarctic ozone: Meteoric control of $\mathrm{HNO}_{3}$, Geophys. Res. Lett., 15, $1-4$.

Rapp, M., J. Hedin, I. Strelnikova, M. Friedrich, J. Gumbel, and F.-J. Lübken (2005), Observations of positively charged nanoparticles in the nighttime polar mesosphere, Geophys. Res. Lett., 32, L23821, doi:10.1029/2005GL024676.

World Meteorological Organization (1998), Scientific assessment of ozone depletion, Rep. 44, World Meteorol. Organ., Geneva, Switzerland.

P. E. Biscaye, Lamont-Doherty Earth Observatory, P.O. Box 1000, Palisades, NY 10964, USA.

D. V. Kent, Department of Geological Sciences, Rutgers University, Piscataway, NJ 08854, USA.

L. Lanci, Faculty of Science and Technology, University of Urbino, Campus Scientifico, Urbino I-61029, Italy. (1lanci@uniurb.it) 